\title{
GRADUALLY USE YOUR SALE
}

\author{
D. Kostova-Pickett
}

University of California, USA

\begin{abstract}
The best pricing strategy will fail unless vendors and managers have sales support and capability to protect it. Trust in negotiations requires trust in pricing. Trust in pricing comes from knowing the value of your products or services. It comes from knowing your client. The support comes from knowing the tricks your customers use to make you lower your price and how to deal with them.
\end{abstract}

Key words: best pricing strategy, trust in pricing, knowing the value

Teach your merchants and managers to negotiate value

The best pricing strategy will fail unless vendors and managers have sales support and capability to protect it. Trust in negotiations requires trust in pricing. Trust in pricing comes from knowing the value of your products or services. It comes from knowing your client. The support comes from knowing the tricks your customers use to make you lower your price and how to deal with them.

\section{It's easy for you to say}

We can't afford to worry about pricing customers. If we do not trust the value of our services to our customers, we have no business doing what we do. We know that if we do not understand how much value we will add to the engagement, we have no work to make a presentation on how we will add value. Start asking how difficult the questions are at the beginning of the engagement, and if the client did not want to answer them, take a deep breath and invite them to go with another salesman. We believe that we are a good solution for our customers. We know we have to act on this trust if we can succeed.

Customers want you to focus on the way you are the same as your competitors to smooth the price level. But you have to focus on how different you are and feel confident about the services you provide to make your decision better. Find out how this difference provides a better customer solution and start acting as if you have decided. Stop acting as a seller of goods. Instead, take this understanding of how you create value, add a dash of arrogance, and build the confidence you need to achieve in today's tough world of negotiating with customers. Get your clients to respect you and want to do business with you. Put the spine in the sales process (2).

\section{The problem with sales}

Yes, we know it will be difficult, but whenever companies tend to lower prices to close the order, they have already lost in their dealings with customers. Every time you do not understand and properly take advantage of the value you create for customers, the money stays on the table. Buyers know this and use all the tactics to get sellers and managers to lower prices. This is a game for customers.

The real problem is not with vendors. These are the managers and compensatory systems that force vendors to worship poker players. This is the end of despair that causes this pointless focus on price. This is a white horse syndrome where managers want to be heroes. Even in cases where managers have switched to profit-based compensation systems for sellers, they often do not work well. This is because sellers will still lower prices to close big orders.

So let's look at the possibilities for making changes. The first step is a bit like a 12-step program. First we have to admit there is a problem. The second step is to recognize that traders and managers need to understand and focus on the value they provide to their customers. They have the right to charge for this value and they have to be confident in the price they set for a deal. The third step is to 
implement programs in the vendor organizations to realize this movement of value on a consistent and systematic basis. We call this placing the backbone in the sales process (3).

Our goal is to make managers see sales times as a scarce source that needs to be used as efficiently and efficiently as possible. When traders are poorly trained, have bad customer motives, are strictly offset, and/or are constantly pushing for a deal at the end of the quarter, good selling and negotiation techniques disappear in the background. As a result, even if the company makes its income, they almost never make their profits, unless they incur more costs. There is a limited time for negotiation. If you do not want to leave money on the table, prepare your sellers and managers for account negotiations. You can do this, but we would suggest you add a few more elements to this process to make it more successful.

\section{Prepare for tough negotiations}

This requires planning. Planning helps vendors to be better prepared for difficult questions and demands from more and more demanding customers. Make sure the top executives of the vendor organization are involved in the planning and agree with the approach. Their involvement gives everyone else the assurance that they will not undermine negotiations as they move forward. Finally, planning increases the likelihood of success regardless of the strategy and approach adopted at the profile level. The more you plan, the more likely you will be to win the deal at a higher, cheaper price. We do not say that high levels of planning are required in all accounts. There are many bills in many business situations where revenue and opportunities are small enough so it's not worth the effort. The call for sales may be more than enough to get in touch with the right people and give the customer a purchasing center for the information they need to make the decision. Some levels of call planning are good discipline, but there are already many basic sales tools and approaches that achieve this. The account planning type we present here is developed as an additional set of complex selling techniques with larger bills to protect the cost and value of the road.

For vendors and teams who are accustomed to doing this kind of work it can be a one-hour planning appointment. For larger and more sophisticated sales, several scheduling sessions that take place over several months may be needed. This process forces the team to ask questions that are not used to asking for the right information to make informed decisions.

Here is the payout. First, it ensures that you do everything you can to identify and meet customer needs. Secondly, it gives you an understanding of the financial consequences of your decisions compared to those of your competitors for the specific client environment. Third, it ensures that you have a deal with all of the people in the customer shopping center. And by asking them the right questions, you assess their factors, strength and strength in the process. Finally, it ensures that you expect two critical reactions: that of the customer and the competitor. This way you have a planned secondary approach instead of having to do it at the beginning of the negotiations. The bottom line is that the preparation increases the probability of avoiding the trap of goods and has a better long-term result in the account, that is, profitable sales growth.

Account planning forces people to connect to different functions within the vendor organization. This means that they not only understand the position of others but also work to prove the overall performance of the company with the customer. The difference here, compared to the organized bulk organization, is that they communicate as a real business team instead of talking to us. (The slider organization does not interact with itself or with other organizations.) They are focused on customer needs. They all strive to ensure that when they improve their own performance, they can show the value of the improvements and gain a better price.

\section{Step 1: Perform a Value Analysis}

The goal is to connect customer needs with what the company offers. Customer value analysis ensures that the products and services you offer are valuable and positioned in a way that reflects that value. Too many times, sales teams and senior staff represent useless rhetoric and customer functions. This undermines the credibility of the team with the client. Step 1 is used to make sure that the company performs in a value-creating manner and presents or discusses these things to customers in a way that highlights tangible value.

First, list all the products, services and activities the company offers to the customer. Turn on product features, service features, technical support, design, customer service, special conditions or supplies to name a few. Check out the catalog and the ad. Specify the things the company says in them as value 
drivers. If they talk about safety, list it. If they speak of quality, indicate it. The more the better.

Second, identify the main competitors. Turn on both good and bad. Do not be fooled by this. If you do not know who your competitors are, contact your customer. It is possible that the buyer does not tell you, but technical or production people will probably do so.

Third, evaluate the results of each competitor. This can be done qualitatively or quantitatively. If done qualitatively, use a simple rating system to sum up important value drivers and their approximate financial benefits. Drill how your bids provide financial value to your customer. If you do not have the answers, ask the client, "Ask them how important their services are as a delivery and technical support, and consult with what keeps them at night and ask how you can help.

\section{Step 2: Run the Purchase Center's analysis}

Buying in most organizations is not an event, it's a process. This process takes place over time. It includes a wide range of people. Everyone has different criteria for choosing a provider. The purpose of this phase is to identify the persons involved, the positions they hold, what are their criteria and how much power and control they have in the process. A useful list of features that individuals can accomplish is developed by Professor Thomas Bonoma of the Harvard Business School (1):

1. The buyer is the actual buyer of the product. Buyers complete the final purchase process with the seller. Depending on the type of product and its stage in the purchase process, different persons may be buyers. In the early stages of qualifying a new product or service, it may be a technical or manufacturing person. Once the purchase becomes routine, the buying function tends to move to the buyer.

2. The wallet processes vendor contacts and controls the flow of information and contacts with other members of the shopping center. The waiter is usually an agent for the purchase. But in the early stages of product or service selection, a security guard can be a middlelevel manager in the customer's organization. The main work of the janitor is to protect the other members of the purchasing center, especially the decision-maker, from contacting the seller.

3. The initiator determines that a product or service is needed. This can be practically everyone in an organization. For services, you may be a higher-level manager. Products may include technical, technical, service, or actual users. For more network purchases, the initiator can be an automated process that determines when stock levels are low.

4. The influence is anyone who can influence the decision-making process, the criteria or the outcome. Many different types of people can actually influence the decision. That is why it is important to draw all participants in the process. If you fail to identify an influential who has a level of power in the process, and that the attacker has a previous connection with a competitor, it is almost always a sign of the danger that you have to do some work to achieve a favorable result.

5. Consumers are the people who actually use the product. It's usually a good idea to contact people who use your products and services to find out if they are satisfied. If you use a competitive product, ask them how they would like to see the improvement.

6. Decision makers are the actual decision makers. They are also known as "foxes," as they often try to hide from outside vendors, usually because their time is valuable and they want to unload this work for their staff. The hard questions of each other will either determine who is the decision maker or you will meet them to answer the difficult questions. We have seen too many lost deals because the team has failed to see the change of power from one person to another. This is because they do not ask the right questions throughout the sales cycle.

The real trick in the buyer's analysis is to use your analysis to determine what type of buyer the customer really is. For example, if you are dealing with a third-party consultant, they will almost always be poker players. They are there to teach customers how to play better poker. They are there to help customers get more discounts for high value products and services. Your bottom line work is to use your understanding of the participants and their strength and control to make an informed judgment of their likely behavior. To do this, you must identify all participants in the purchasing center. Then give priority. What are their individual decision-making criteria - in other words, what are their needs?

You get this information through technical techniques for a deep interview. Yes, everyone in the center has a different set of needs. That is why the next thing you do is assess the level of power and control over the process. When doing this, it is important to remember that third-party gatekeepers and consultants always exaggerate their power in the process. By dealing with a number of "informants," you 
develop a much better sense of where the real control is.

Recognize that a person can fill several positions in the purchasing center. For example, the buyer and concierge will in many cases be buyers. As purchases become routine, purchasing centers receive less volume and control is passed on to the buyer.

There is one last point in purchasing centers. Expect them to change without warning. Many traders are burned when this happens. Sometimes these changes happen when a new member suddenly gets into the mix. Regardless of the position of the purchasing center that a member can perform, they may result in a change in the criteria and the process of play.

Be especially careful if organizational change in buyout centers is organized because they often signal a significant change in the purchasing behavior of the account.

\section{Step 3: Evaluate the likely purchasing behavior}

Buyers of value and relationships are pretty easy to identify. They are more open and honest for their real needs. They will tell you what they want if you ask the right questions. But do not forget that no matter how much we talk about value, not all customers are willing to pay for it. To make matters worse, those who do not want to pay fall into two categories. The first are buyers at prices. These are those who do not want value. They take care only to get the lowest possible price. The second group is poker players. They have all sorts of tricks to make suppliers tremble and sneak in the talks. The important question here is to predict what their approach will be and to be prepared with the right set of answers. You build price pride along the way. Purchasing centers can and will show different behaviors. Technical teams want value, and purchasing agents want a low price.

Your task is to assess the level of control of each faction and to determine what their real behavior is.

\section{Step 4: Define your coverage strategy}

The goal here is to take the Customer Purchase Center analysis and their possible purchase approach and develop a profile coverage strategy to increase the likelihood of success with the account. It is important to make sure that the people identified in the purchasing center are covered by the appropriate managers in the sales organization. You do not want to waste time by calling people who are not interested, and you do not need to see salespeople representatives. In fact, buyers of prices should not see traders or senior managers. They prefer to use the phone.

Senior managers need to be trained on the value of sales as much as the seller. In fact, they can often send a strong signal of how the negotiations will be conducted, taking strong positions on the value given and what your expectations are during the negotiations. Finally, the Sales Coordinator is responsible for ensuring that all senior managers will support the profile strategy rather than fold in the middle of the negotiations.

\section{Step 5: Propose development}

The goal of this phase is to translate the valuable needs of players into the purchasing center and the evaluation of your purchasing behavior in the strategy of offering a meaningful account. The point is that you need to develop a high-level offering structure that can be summed up in important key elements. If you are not dealing with a real buyer at prices, these key elements need to be backed by a calculation that shows the financial benefit. This calculation should be supported by an analysis of the relationship between the stated value factors and the key elements of the supply.

The service and maintenance discussion is even more important than the product. Many products can become goods but services are not. These are the true differentiations. Make sure you have identified important services and included them in a high value package. And remove them from the low value package. Getting the services from the low-priced package is the key to the poker player saying, "We need it." Or, maybe they will say, "Your competitors are ready to do that."

The price you specify needs to be verified. Why do you think the price will work? What is your support for why the prices you have charged are reasonable? If they are higher than competitors, why do you think you should be able to charge them? You must have ready answers and maybe you do not have time to get good answers.

Finally, what are the critical success factors for this negotiation? What do you need to do to really do this? What can happen to inflate the process? What do you need to do to make sure that you effectively communicate your value and support proposal? Do you need better references? There are a number of questions 
that need to be addressed and considered to make sure you get the best possible result.

\section{Step 6: Develop the Core Negotiating Approach}

At this stage you have to get a number of questions in order. What are the likely behaviors of the client and how will you deal with it? What are the specific value reports and what kind of return on investment analysis do you need to quantify? Where do you stand with your competitors?

The added question of this phase is related to possible closure devices. These are the things you can throw at the table to close the deal. These are usually things like the extra discount. The problem is that this continues to focus on the price. That's why it might be a better idea to have some value-based closing devices. Additional training, services, engineering or design assistance and payment terms are all that can be used. Yes, sometimes you want to charge for these things, but it's usually a good idea to get closer to move the client across the edge to place the order. Do you remember the initial story in this chapter? The client uses a 2 cent discount to force the client to close. The closing devices should be held in your back pocket and not thrown too early.

The final step is to determine the cost price. This is the price for which you have decided it is the price below which you should not go. This is the price that gives you a certain level of reasonable profit. This is also the departure threshold. Everyone in the team must agree or at least honor the number before the negotiations. At the last moment there can't be panic mood and give up the price. The overall reliability of the company is set. Buyers know this. Yes, that requires courage.

\section{Step 7: Determine the customer's expected response}

This is probably the most difficult part. This requires a good understanding of the people in the customer shopping center. You will never know for sure but you can work to predict where the client will not agree on the key points you are trying to do. For these expected points of disagreement, you should either have anecdotal or quantitative support. The same preparation is also required for the questions you may ask. Technical people can ask for the documentation. You may want to provide technical manuals or provide them online.

Who do you think their last preference will be to be a vendor? If you are not, you have to be honest with yourself. Perhaps it is a good time to quit the talks. Some members of the purchasing team may not want to leave, but if the person who writes the checks has a connection with another seller, you probably lose time. This is the biggest mistake you can make during this process. During the opening process, you may find that the head of senior management has a connection with another company. The other members of the purchasing center persuade you to continue the process because they are supposed to be like you. But when the decision is made, the foreman almost always wins the day.

It's a good idea to take the team on the account and split it up half. Make them spend time and answer each of the questions. This will force all of them to engage and think through the customer process. He will give the whole team, after returning together, the ability to compare and discuss, how different answers to the questions have been answered.

\section{Step 8: Develop a Secondary Negotiating Strategy}

Your goal here is to prepare answers for both the client's response to your initial strategy and the competitor's response. What will you do if your competitor drops? Can you provide good answers to the questions you expect? Do you have the technical capabilities to handle network calls and customer service if needed? Remember that preparation is the question of this process. "Chance favors the prepared," as the slogan says.

\section{How about RFP?}

At this point, it's worth spending a few minutes when you talk about RFPs. RFP is often a sign that the client is not a buyer of relationships and will probably not be a buyer of value. Especially if they do not have identified selection criteria that give higher value providers a chance to win. This means that RFPs come mostly from buyers or poker players. Before we give you a recipe, please answer the following questions. What percentage of your RFP points do you earn? You will be surprised how many managers do not know! The next question is How long does your people spend on the answers to each RFP? If this is more than an hour and your near rate is low, you lose resources matching RFPs.

The dominant account vendors meet customers' RFPs too often. This is especially true when RFP means that the change in purchasing a liability of a technical person or a consumer to a purchasing agent. This is also the case when there is a third party consultant 
for manipulating the bidding process. These people take the products and services provided by primary producers, and leave them to apply with a wide range of suppliers, many of which are of low value. The worst thing a domineering person can do is to respond to REP. When they do, they will either have to significantly reduce their cost in order to win the business, or they will have to lose their bid for a low-value seller. If this means that customers are moving from buyer to buyer at a price, you need to have a low-value bid. "If the client becomes a poker player, failing to respond is an excellent way to call a bluff. That it undermines the buyer's trust with the rest of the purchasing center, but if you lose your business, you can do everything in your power to keep your trust in. What about reverse auctions? Orders or e-auction is a tool used in business-to-business orders. It is a type of auction where buyer and seller roles are reversed, with the primary goal of lowering purchase prices, in a simple auction (also known as a forward auction) buyers compete in order to get a good or service, buyers compete in order to get a business in the reverse auction, with rewards to benefit from poker players who decide to place their suppliers rolling through hours or days with an online bidding process that shows how unnamed competitors respond to an RFP and enables managers to respond to real practice, based on time. Why buyers do this? They do it because it works. This leads to lower prices.

Whenever a seller responds to an offer or an RFP, he has to stop, ask questions and get answers to a number of basic questions. They have to assess whether this will be a fair offer to an equal or whether a potential customer simply conducts a fishing expedition. We recommend that companies receive feedback from the prospects of a number of key issues before agreeing to participate in the process:

1. What specific business problem are you trying to resolve?

2. Who and / or what does it mean?

3. What is the probability of returning if you solve the problem?

4. What are the criteria for choosing a vendor to help you?

5. What is the process of choosing a vendor to help you?

6. What is the final approval process for the project?

7. What is the final signing and what is the position of this person?

8. Is there an approved budget?

9. What is this?
10. If there is no budget, what is the point of what this should cost?

Our up-to-date list is much longer than that, but this list goes to the common point. The result of asking these questions is that you often find that the people who bundle these offers have not considered enough to assure you they are serious about the claim. Sometimes it's a casual attempt to see how vendors will react without a real intention of buying something. Sometimes it's an attempt to push an idea and see how vendors respond to them. Of course, they want to buy something, but they also want suppliers to train them on the road. This is good if you have good chances to win a business. But if you do not, let the winner train the client. Or make sure you get paid to do it.

The next time the buyer tries to tell you that you are a product, take a deep breath and tell him that if they want goods, there are six more competitors in your business from which they can be bought. Talk about everything you do to help them add value to what they are doing. Talk about the things your company does to improve the quality of your products and services for them. Talk about things your company does for the industry.

We assume that this process is not easy to implement in the real world. This requires confidence in your value. This leads to some risk. In other words, do you have the power to act according to the value you offer? There is no easy answer to this question, but he has to be asked repeatedly. Pricing managers avoid this question only with the enormous cost of moving away from those they serve. Price leaders will make mistakes from time to time, but when they test each sales and lost opportunity, they will find the power they need to overcome.

\section{REFERENCES}

1. Thomas Bonoma, "Major Sales, Who Really Does the Buying?" Harvard Business Review, May-June 1992.

2. Timothy Aeppel, "Seeking to Perfect Prices, CEO Tears Up the Rules," Wall Street Journal, March 27, 2007.

3. Tom Peters and Robert Waterman. In Search of Excellence- Lessons from America's Best-Run Companies, New York: HarperCollins.

4. Bill George. True North: Discover Your Authentic Leadership, New York: JosseyBass, 2007. 